\title{
Decade review (1999-2009): progress of application of artificial intelligence tools in student diagnosis
}

\author{
Athanasios S. Drigas*, Katerina Argyri and \\ John Vrettaros \\ NCSR DEMOKRITOS, \\ Institute of Informatics and Telecommunications, \\ Net Media Lab, \\ Ag. Paraskevi, 15310, Athens, Greece \\ E-mail: dr@iit.demokritos.gr \\ E-mail: akate82@gmail.com \\ E-mail: jvr@iit.demokritos.gr \\ ${ }^{*}$ Corresponding author
}

\begin{abstract}
Over the last decade, artificial intelligence has offered a wide range of tools that have proved to be of vital importance for educational research. Indeed, logic, classifiers and machine learning methods, probabilistic techniques for uncertain reasoning as well as search and optimisation algorithms are only several among the various approaches that artificial intelligence has offered in dealing with real life problems. This paper attempts to explore the research that has been conducted on the application of the most typical and popular soft computing techniques [fuzzy logic, neural networks, Bayesian networks, genetic programming and hybrid approaches such as neurofuzzy systems and genetic programming neural networks (GPNNs)] in student modelling over the decade 1999-2009. This latest research trend is a part of every intelligent tutoring system and aims at generating and updating a student model in order to modify learning content to fit individual needs or to provide reliable assessment and feedback to student's answers. In this paper, we make a brief presentation of methods used so as to point out their qualities and then we describe the most representative studies sought in the decade of our interest after classifying them according to the principal aim they attempted to serve.
\end{abstract}

Keywords: student modelling; student diagnosis; fuzzy logic; neural networks; genetic programming; student assessment; student evaluation; adaptive learning.

Reference to this paper should be made as follows: Drigas, A.S., Argyri, K. and Vrettaros, J. (2009) 'Decade review (1999-2009): progress of application of artificial intelligence tools in student diagnosis', Int. J. Social and Humanistic Computing, Vol. 1, No. 2, pp.175-191.

Biographical notes: A.S. Drigas is a Senior Researcher at IIT-NCSR Demokritos. He is the Coordinator of Telecoms and Founder of Net Media Lab since 1996. From 1985 to 1999 he was the Operational Manager of the Greek Academic Network. He is the Coordinator of several international and national projects in the fields of ICTs - Telecoms, e-services (e-learning, e-psychology, e-government, e-inclusion, e-culture, e-business etc). He has published more than 200 international and national articles in ICTs, 7 books, 25 educational CD-Roms and several patents. 
Katerina Argyri obtained her diploma in 'Applied Mathematical and Physical Sciences' in 2007 after graduating from National Technical University of Athens. She is currently completing her Postgraduate studies in 'Applied Mathematical Sciences' with specialisation in Computational Mathematics at the same University and she is an Associate of Net Media Lab.

John Vrettaros is a Professor of Physics and Informatics and a Pedagogist. $\mathrm{He}$ is an Associate Researcher at the Institute of Informatics \& Telecommunications of N.C.S.R. Demokritos. He is the Coordinator of e-learning projects within Net Media Lab and he has published more than 40 international and national articles in ICTs, 4 books, 25 educational CD-Roms and several patents.

\section{Introduction}

Traditionally, artificial intelligence aims at simulating filtering information, handling constraints, recognising patterns and making logical inferences as well as other activities necessary in order to deal with real life problems in an automated way. In the last decades, each and every one of the activities mentioned above have been a real challenge, as the researchers' community realised that they are of significant practical value for learning sciences especially when seeking to obtain in an automatic way active and reflective learning just like all learning theories suggest.

Artificial intelligence has a wide range of applications in the educational field and new directions are constantly given in educational research. Among the most typical of them are several areas such as intelligent information retrieval (Drigas and Vrettaros, 2004), natural language processing in order to accomplish tasks such as evaluation of student's work (McAlister and Wermter, 1999), intelligent agents (Baylor, 1999) [in the wider field of expert systems (Liao, 2005)], robotics (Alimisis et al., 2007), intelligent virtual environments (de Antonio et al., 2005), voice and image recognition (Salleh et al., 2004) especially used for data input in cases of learning or physical impairments and e-tutoring (Vrettaros et al., 2008).

In this paper, we will focus on the techniques incorporated during last decade (1999-2009) and on student modelling as it seems to be one of the latest research trends and in the same time one of the most significant and challenging tasks for an instructor, let alone for an intelligent tutoring system.

According to Stathakopoulou et al. (2005), student modelling is consisted of two components: the student model and the diagnostic module. The student model is one of the components of an intelligent tutoring system which provides a description of student-related information such as his knowledge level, skills or even preferences while diagnosis is the inference process which in the end updates the student model.

Brusilovsky and Eklund (1998) suggest that the student model keeps track of students' state of mind on the basis of their responses. Consequently, reliable student modelling comes up via careful student assessment, the process that allows the expert to diagnose the learner's mental state and knowledge status in order to check on the efficiency of teaching and to detect possible learning deficiencies.

The idea of the creation of a student model via an automated way is a realistic and hopeful one since according to Frias-Martinez et al. (2005), a user (in the more 
generalised user modelling problem) leaves trail while using a hypermedia system and these data can be stored and used in order to generate further information, patterns and predictions.

The popularity of this task is more than justified if one takes into consideration the fact that 'student model enables these systems [adaptive and intelligent web-based educational systems (AIWBESs)] provide individualised course content and study support to help students with different background and knowledge status to achieve their learning objectives' (Homsi et al., 2008). After all, high adaptability in teaching, a goal strongly connected with student diagnosis, has proved to be a fruitful way to maximise learning results (Lane, 2006). Indeed, studies sought have shown that students process knowledge and learn in different ways and that is why researchers strongly believe that students learn in an efficient way when teaching is tailored according to their personal learning style and other individual characteristics (Haron and Salim, 2005).

In this context, many artificial intelligence techniques keep on triggering researchers' attention and their incorporation in more and more aspects of the educational field is being adopted.

To name just a few, neural networks, Bayesian networks, Markov models, control theory, fuzzy logic as well as search methods such as genetic and evolutionary algorithms are used to serve this purpose, alone, in all possible combinations among them, or in combination with different techniques, such as other machine learning algorithms for more efficiency.

\section{Artificial intelligence in student modelling}

As it was mentioned above, student modelling has been a real challenge for researchers in the educational field especially over the last decade. But in order for that to be achieved, the knowledge as well as the experience of the educational expert has to be represented in a precise way, and most importantly, the inference process used by the expert must be modelled and simulated (Grigoriadou et al., 2002).

The most useful tools for approaching those goals and finally obtaining reliable student diagnosis will be described in a few words and the qualities of each technique will be pointed out.

\subsection{Artificial intelligence methods used}

Artificial neural networks (ANNs) are computational models, inspired by the way biological neurons process information. These decision-making tools are weighted interconnected networks of artificial neurons and have the ability of 'learning' through experience via algorithms. Currently, neural networks become more and more popular in various scientific fields including the educational one. Just a few of their significant abilities are the fact that they recognise patterns, they derive meaning from vague data and not only they learn in an adaptive way, but they also identify matching in similar cases (Stathakopoulou et al., 2005). In education, the qualities of the neural networks are used in order to simulate and monitor a learner's cognitive progress (Ali and Ghatol, 2004) and to obtain classification of students sharing common characteristics. 
Fuzzy logic is a multivalued version of Boolean logic based on fuzzy set theory. It was introduced [formally by Zadeh (1965) who axiomatised fuzzy set theory] in order to handle uncertainty in everyday problems caused by imprecise and incomplete data, as well as human subjectivity. A fuzzy set is defined as an ordered set $\left(x, u_{A}(x)\right)$, ó $\pi$ ov $x \in X$ $\kappa \alpha l u_{A}(x) \in[0,1]$, equipped with a membership function $\mu_{A}(x): X \rightarrow[0,1]$, where

$$
\mu_{\mathrm{A}}(x)= \begin{cases}1, & x \text { absolutely in } A \\ 0, & x \text { absolutely not in } A . \\ (0,1), & x \text { partially in } A\end{cases}
$$

The value $u_{A}(x)$ is called degree of membership or membership value. Consequently, one could say that Boolean logic is nothing but a generalisation of fuzzy logic since both versions coincide when membership function is allowed to have only two possible values $(0 / 1)$. Fuzzy logic is gaining more and more popularity (even in business world since already by middle nineties more than 6.1 billion dollars were gained in a year just in Japanese fuzzy logic industry) and according to Stathakopoulou et al. (2005), the application of fuzzy logic principles in student modelling is more than attractive since it overcomes computational complexity issues and thanks to its human-like nature is user and designer friendly. In education, researchers try to take advantage of the way that fuzzy logic model human decision-making via if-then rules when seeking to achieve diagnosis of a student's knowledge level. Hawkes et al. (1990) were among the first to adopt fuzzy student modelling.

A Bayesian network is a directed acyclic graph (DAG) with its nodes representing random variables or events and with its edges encoding probabilistic relationships (dependence, independence, causality, etc.) among the variables. When incorporating statistical methods, this tool becomes very powerful for data analysis. Indeed, Bayesian networks offer a very intuitive visualisation which describes dependencies among variables, an easy way to learn causal relationships, to incorporate prior knowledge in data as well as to reduce the possibility of overfitting of the data. Additionally, according to Li et al. (2004), they offer efficient reasoning and semantic representation and provide an effective way to deal with prediction, classification and clustering especially when combined with prior knowledge and observed data. Bayesian networks have been applied successfully in various fields such as medical diagnosis [Pathfinder (Heckerman et al., 1989) and DIAVAL (Díez, 1994)] and diagnosis of mechanical failures.

In 1992, Villano was the first to suggest the application of probabilistic student models. Since then, various similar attempts have taken place even though high computational complexity discourages relevant research.

Genetic programming is a search algorithm used to identify the most efficient candidates for a specific task via the creation of a computer programme. It is based on biological evolution principles, namely the Darwinian survival of the fittest. The steps that a genetic algorithm follows are presented below:

- assess the initial population according to specified criteria

- if a possible solution satisfies the criteria, stop

- select the most satisfying candidate and reproduce (via crossover and mutation)

- return to the first step. 
In education, genetic algorithms are a valuable tool since they can be used to derive a reliable expert knowledge representation.

Last but not least, many hybrid approaches are among the most popular choices of educational researchers since through research conducted so far, they have proved to deal better with complexity and vagueness issues. Among the most popular synergies are neuro-fuzzy systems and genetic programming neural network (GPNN) methodology. In the first case, many problems coming up during separate use of the two technologies are being overcome since their combination offers a fuzzy inference system which uses a neural network learning process (Al-Hammadi and Milne, 2003). The latter approach takes advantage of the fact that genetic algorithms can provide optimal network architectures (Siddique and Tokhi, 2001). In other words, genetic programming is applied on an initial population of neural networks in order to obtain an ideal one via reproduction, crossover and mutation.

\subsection{Literature sources and filtering}

During the last decades and especially in the last one, research of artificial intelligence in education has expanded in so many levels that it would be impossible for someone to study in detail all kinds of research achievements. Consequently, we chose to analyse a subset of all the papers examined, the one that covers issues useful in obtaining accurate and reliable student modelling. We were initially based on a range of 200 papers analysing the subject under study. The papers we studied were retrieved from platforms such as ISI Web of Knowledge, database bibliography sites such as Digital Bibliography \& Library Project (DBLP) and Scopus as well as web search engines such as Google Scholar. The research was conducted combining the following keywords: student model, student modelling, student diagnosis, intelligent learning systems (ILSs), intelligent tutoring systems, fuzzy logic, neural networks, genetic programming, neuro-fuzzy systems, learning styles, adaptive learning and assessment. So, after completing a detailed literature review and a filtering with respect to the publication year, the artificial intelligence methods used and the main relevant conferences and journals, we came up with the final selection of papers. In the end, we came to the conclusion that the most meaningful way to organise the research in the particular field is to categorise the studies conducted according to the purpose they attempted to serve.

\section{State of the art}

First of all, we need to observe that one common goal that the majority of papers under study shared was the classification of the students, namely the attempt for every student to be mapped in one of several predefined groups. The classification purpose though was different from study to study. There were researchers that chose to achieve this categorisation giving emphasis to the individual characteristics (such as learning style) of a student and so the enhancement of individualised learning was the actual goal. There where also researchers that gave emphasis to coming up with a reliable assessment method of students cognitive state some of them seeking to the traditional students' assessment and ordering and others to predict students' future performance or even to fix in time serious learning deficiencies. 


\subsection{Studies classifying students according to their knowledge level/modelling their future performance}

Ma and Zhou (2000) implemented a fuzzy set approach in order to assess the outcomes of learning process. In this paper, fuzzy set principles were applied to the determination of the assessment criteria and the corresponding weights and finally students' performance was evaluated on a fuzzy grading scale according to the selected criteria. The application of this method as well as the use of a group decision support system (GDSS) (Ma, 1996) was attempted in the Department of Information Systems at the City University of Hong Kong (Zhou et al., 1999; Kwok and Ma, 1999). With the help of a control group, experimental results have proved that this method empowers a deeper approach of learning (Ma and Zhou, 2000).

Olds et al. (2000) have implemented a software package called Cogito aiming at accurate and inexpensive measurement of the students' ability to think critically acquired so far. Cogito makes use of a neural network in order to obtain pattern recognition in learners' data and finally matching with models of intellectual development that have come up via traditional interviews. Cogito keeps being developed, retraining the neural network with new data extracted from interviews on 60 additional subjects, updating its interface and forming extra partnerships with several institutions (Olds et al., 2000).

Weon and Kim (2001) introduced a learning evaluation system aiming at providing more flexible results comparing to numerical results which come up applying traditional assessment methods. This approach makes use of fuzzy linguistic variables representing each question and then evaluates a score taking into account the membership degree of uncertainty factors. This method has been tested on fourth grade students of an elementary school with promising results (Weon and Kim, 2001).

According to VanLehn and Niu (2001), the ANDES physics tutoring system is equipped with a student modeller which uses Bayesian networks. The principal aim that the network serves is determination of the rules that the student has probably mastered. Since those probabilities constantly change, ANDES needed a dynamic belief network (Russell and Norvig, 1995). In ANDES, every student has his personal file that contains for every rule, the probability that the student has mastered the rule. When a student is dealing with a problem, a Bayesian network is created and as the student solves the problem the network is constantly updated. Once the problem is closed, the posterior probabilities are stored in the student's file (VanLehn and Niu, 2001).

Al-Hammadi and Milne (2004) designed a student classification method using neurofuzzy techniques in order to obtain learners' performance prediction before admission to college. The learner's secondary school marks and his college entry test performance are the inputs of the neuro-fuzzy system while it outputs the student's performance in the first semester of his college studies. This system, NEFCLASS, was proposed for pattern recognition and fuzzy data analysis. Tests have been conducted using actual student exam results and the participants were classified into three categories according to the expected performance with encouraging results in most cases (Al-Hammadi and Milne, 2004).

Vrettaros et al. (2004) developed a diagnostic system of taxonomies based on fuzzy logic which is mostly ideal for e-learning systems (Drigas et al., 2004a, 2004b). The procedure described by the authors consists of an initial processing of the filled up questionnaires, students' categorisation into level in five separate theme sections and students' categorisation according to the given answers into one of the predefined knowledge levels. This system has been tested on 100 high school and senior high school 
students in mathematics and results were in significant accordance with cognitive science expert's results (Vrettaros et al., 2004) (Figure 1).

Figure 1 Inputs and output of the system (see online version for colours)

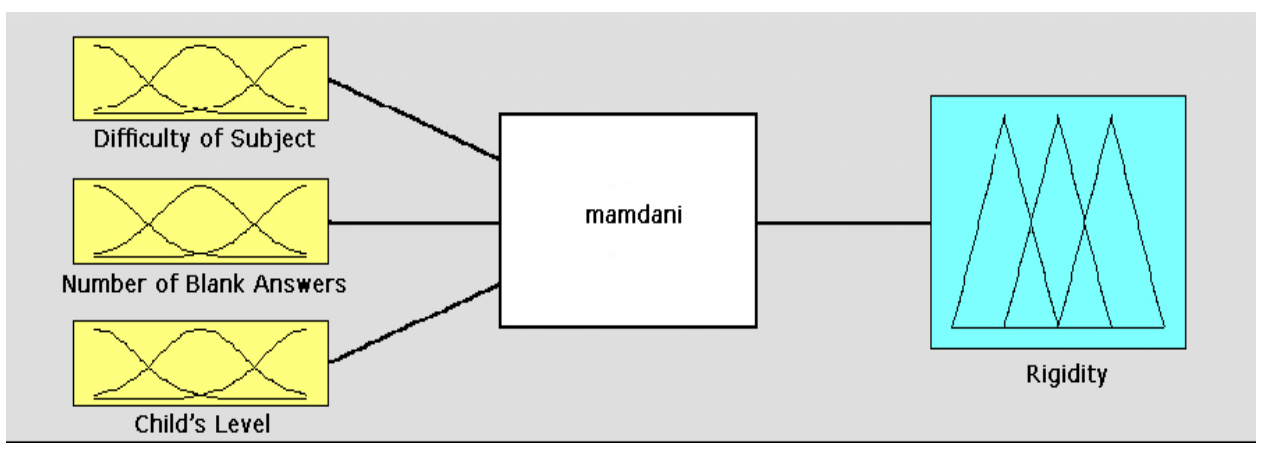

Source: Drigas et al. (2004b)

Nykänen (2006) introduced a fuzzy system aiming at predicting students' performance and finally preventing students from failing, dealing in time with serious learning deficiencies and giving extra assistance if needed. Experiments have been conducted using two datasets which describe students' performance in a university mathematics course in 2003 and 2004 at the Tampere University of Technology, Finland (Nykänen, 2006).

Sevarac (2006) used a neuro-fuzzy reasoner (NFR) system ideal for e-learning applications performing student modelling in a flexible way since it can be easily tailored to the teacher's preferences. As an application, the author presents the use of the system for students' classification reasons according to the test results and the time of test completion. The classification rules were taken from a human expert and the predefined classes were bad, good, very good and excellent. The system went through an initial testing with very satisfying success rate and it was also successfully tested through an actual e-learning application called Multitutor (Sevarac, 2006).

Desmarais and Gagnon (2006) explored the use of two Bayesian frameworks (of one typical Bayesian network and of a constrained version under the assumption of local independence) in an attempt to predict item outcome. The two approaches were compared over their predictive power and their performance was measured using data from real tests to conduct simulations. The experiment attempts to simulate the assessment process. After the choice of an item, the result of the answer, whether it is a success or a failure, is fed to the inference algorithm. Although both methods turn out to give accurate predictions, the constrained one obtains better predictive results (Desmarais and Gagnon, 2006).

Wei and Blank (2006) conducted an experiment in order to study the sufficiency of atomic Bayesian networks for student models. Indeed, a student model was presented, aiming at diagnosis of student's knowledge state in CIMEL-ITS, an intelligent tutoring system that helps beginners learn object-oriented design in a CS1 course (Blank et al., 2005; Moritz and Blank, 2005; Moritz et al., 2005; Wei et al., 2005). After using 240 simulated students, ABNs were evaluated as very powerful tools as they seem to be able to offer not only accurate but also quick student diagnosis (Wei and Blank, 2006). 
Chang et al. (2006) presented an effort to model a student's changing knowledge state during skill teaching. For this purpose, they introduced a tool called Bayes Net ToolkitSM that helps training and evaluating dynamic Bayesian networks. It inputs a student model (XML file) and outputs BNT MATLAB code to train and evaluate this model. The data were extracted from 360 children between six and eight years old who used Project LISTEN's Reading Tutor (Mostow and Aist, 2001) in the 2002-2003 school year. The children were separated into two groups (training and testing set) and a dynamic Bayesian network was set up using BNT-SM. This paper describes dynamic Bayesian networks as a very powerful tool for student modelling (Chang et al., 2006).

Zapata-Rivera (2007) adopted the indirectly visible Bayesian student modelling approach which was implemented in the context of assessment-based learning environment (ABLE) for English grammar that included: a Bayesian student model, an indirectly visible student model and pedagogical agents. Here, pedagogical agents question the Bayesian student model in order to implement adaptive algorithms. English ABLE tools and interface were tested using 149 native Spanish speakers with encouraging results (Zapata-Rivera, 2007).

Figure 2 The steps of the assessment system

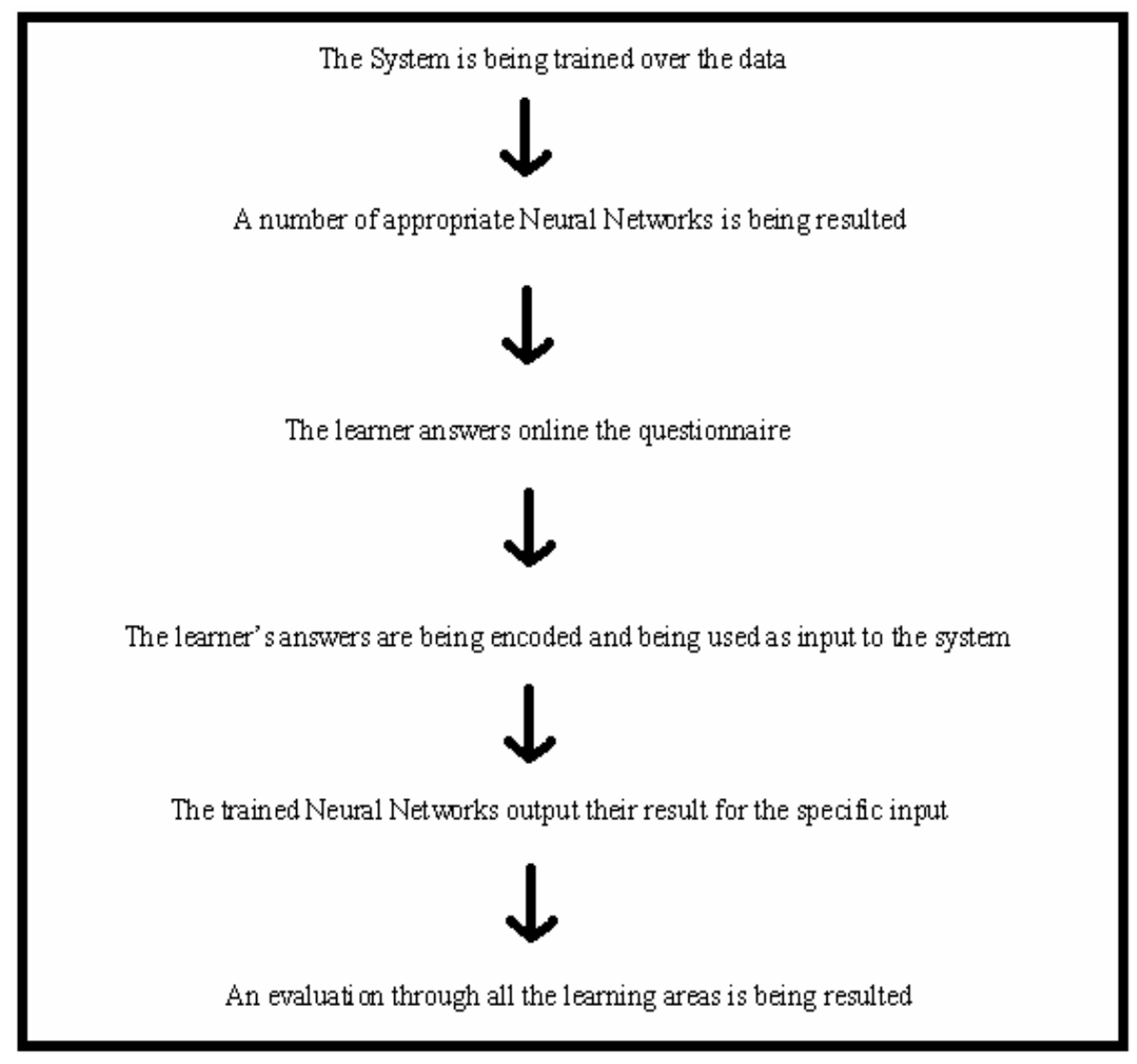

Source: Vrettaros et al. (2008) 
Vrettaros et al. (2008) tried to obtain learners' assessment evaluating their answers according to a number of examined criteria. The final aim was to equip the e-learning platform with a reliable evaluation tool substituting an e-tutor. This was attempted with the implementation of a neural network genetic programming method. The GPNN system was trained through students' answers as well as the assessment given by an expert, and to be more specific, through actual data extracted from an educational project called DEDALOS. Genetic programming was incorporated in the neural network approach (as an alternative to a backpropagation algorithm) for optimisation reasons such as quick convergence to the solution (Vrettaros et al., 2008) (Figure 2).

Wang and Chen (2008) suggested a new way of evaluating students' answerscripts with the use of fuzzy numbers in combination with degrees of confidence of the evaluator and considering a degree of optimism for each evaluator to achieve flexibility. Nine satisfaction levels represented by triangular fuzzy numbers were used for students' classification (Wang and Chen, 2008). Experimental results indicated that the approach proposed in this paper is an intelligent and stable one comparing to older methods proposed (Biswas, 1995; Chen and Lee, 1999).

\subsection{Studies inferring individual characteristics and aiming at adaptive learning}

Hwang (1999) came up with an intelligent computer-assisted testing and diagnostic system which empowered individualised learning as it had the ability of providing dynamic tests according to the learner's characteristics. This system is based on fuzzy reasoning principles and enhances the improvement of students' learning status. This is obtained giving the learner the choice to adjust the parameters according to which the test items differentiate, offering guidance after the learner has done the test as well as offering indications in case of learning deficiencies. The system consists of a student information database, an item bank, a Java-based interface, a testing and diagnostic unit as well as a fuzzy interface. For the evaluation of the instructing system, a group of 30 students from a primary school was used with encouraging results (Hwang, 1999).

Kinshuk et al. (2001) have used a fuzzy propagation approach which is based in a neuro-fuzzy system aiming at maximising adaptability in business education tutoring. The student's data that come up during interaction are being input to the FBP in order for the network to be trained. The system described by the authors consists of the interactive mode where learning takes place and of the assignment mode where assessment of the student's success in the first mode takes place (Kinshuk et al., 2001).

Shen et al. (2001) constructed an assessment system, part of a studentoriented network system, ideal for web-based distance learning. It makes use of several artificial intelligence technologies such as neural networks, fuzzy set theory, genetic and backpropagation algorithms in order to succeed not only in assessing and classifying students, but also in constructing types of student profiles so as to empower the adaptability of the learning content to each individual's needs. Via those technologies, the results are impressive even in cases where data is extremely vague and subjective (Shen et al., 2001).

Grigoriadou et al. (2002) have attempted to achieve precise student diagnosis incorporating fuzzy logic and multicriteria decision-making in intelligent system for personalised instruction in a remote environment (INSPIRE), a web-based adaptive 
educational hypermedia system (AEHS) (Brusilovsky, 1996). Via this combination, enhancement of adaptability of INSPIRE is being achieved. The authors focus on student's diagnostic module which aims at student's classification according to his knowledge level and learning style. The method described has been tested over 20 postgraduate students of the Department of Informatics and Telecommunications of the University of Athens and proved to offer students' assessment as much reliable as the one performed by a human teacher (Grigoriadou et al., 2002).

de Arriaga et al. (2003) created an ILS based on multi-agent architectures. Via this system, using a fuzzy set for each individual and for each one of the basic learning styles, the determination of the learning style is obtained. Secondly, the student's knowledge level as well as the learning ability is being assessed, and finally, the overall student grade comes up. This technique has already been used in TUTOR3, and according to the results, the assessment performed is reliable and the individualisation of the learning process is enhanced (de Arriaga et al., 2003).

Stathakopoulou et al. (2005) attempted to create and update a student model identifying students' individual characteristics. For this purpose, a neural network-based fuzzy model was implemented where the fuzzy component aimed at simulating human decision-making and the neural networks were incorporated to provide it with learning and generalisation abilities. Neural networks were trained through actual students' profiles. The diagnosis that came up with the help of the model was compared to the one based on the judgement of a group of five teachers and the model proved to handle uncertainty in a smooth way even if we are dealing with marginal cases (Stathakopoulou et al., 2005).

Vomlel (2003) gave an accurate description of how a Bayesian network model used in an adaptive test can be built. The paper was based on a semester project during which aimed at designing an adaptive test of students' knowledge of basic operations with fractions. According to the author, the particular application of Bayesian networks may be described as generalisation of the multidimensional item response theory (IRT) which is the typical approach when seeking to obtain educational and psychological testing since the 1960s. The presented application is believed to offer accurate modelling of the student reasoning process (Vomlel, 2003).

Mir Sadique and Ghatol (2004) attempted to use the architecture of the adaptive neuro-fuzzy inference system (ANFIS) in the field of intelligent tutoring systems aiming at reliable and precise student modelling. According to the authors' description, learners are tested in concept understanding, memorising skills and possible misconceptions and results of these tests are given as input in the inference system. Finally, learners' performance is categorised as poor, fair, good or excellent. This method has proved to give results matching to those that come up from human teachers' evaluation (Mir Sadique and Ghatol, 2004).

According to de Arriaga et al. (2005), FINANCE, a system for learning financial accounting and business analysis based on a fuzzy intelligent research system called NEOCAMPUS2, offers a full and reliable student model. According to experimental results with the necessary use of control groups, FINANCE turned out to be a fruitful way of learners' assessment especially comparing to the traditional evaluation methods. Most important of all, this method achieved significant acceleration of the novices' turning into experts (more than $25 \%$ time needed for the control groups) (de Arriaga et al., 2005). 
Moebs et al. (2007) suggested a set of tools and techniques for the tailoring of blended learning scenarios to the learning styles of learners. The tools consisted of four components, the first of which described a probabilistic method to automatically estimate the learning style of a student based on Felder's index of learning style (Felder and Spurlin, 2005). This paper made use of a Bayesian network in order to diagnose a student's learning style from observable data characterising the blended learning material and the student's performance (Moebs et al., 2007).

Yang et al. (2007) constructed a Bayesian network structure in a student model proving the effectiveness of the particular method in determining if a student masters a particular knowledge item or not. Student's learning condition is abstractly expressed by extracting information from students' interaction with the machine interface and by using probability mechanism to infer. The proposed student model attempts to turn the abstract expression into a clearer one in order to tailor learning process according to the requirements of a particular user (Yang et al., 2007).

Carmona et al. (2007) attempted to detect students' learning preferences with the use of adaptive machine learning algorithms. Here, an initial student model and a decision model for each individual are built. Then, the authors make use of a dynamic Bayesian network (Dean and Kanazawa, 1989) in order to design a learning style model. The model is initialised with the student's scores obtained to the Index of Learning Style Questionnaire (ILSQ) (Felder and Soloman, 2007), and then, it is updated through student's selections. The decision model, which decides whether a resource is interesting to a student or not, is based on Bayesian network classifiers (BNCs) (Friedman et al., 1997). The model proposed in this paper has turned out to be very useful in e-learning system especially when dealing with large volumes of available information.

Homsi et al. (2008) introduced the AIWBES which makes use of an algorithm based on Fuzzy-ART2 neural network and hidden Markov model (HMM), which is a stochastic method. Reliable student modelling is attempted through two stages, the initialising where personal and educational information is gathered and the updating one which updates the knowledge status. The goal of this system is assessing learners taking into consideration five parameters and determining their knowledge level in order to categorise them in six levels. This study attempted a hybrid approach combining a machine learning algorithm with a soft computing synergy and according to experimental results, the combination which was used achieved a precise learners' categorisation (Homsi et al., 2008).

Table 1 Papers categorisation

\begin{tabular}{|c|c|c|c|c|}
\hline Title & Year & $\begin{array}{l}\text { Individual } \\
\text { characteristics } \\
\text { ladaptive } \\
\text { learning }\end{array}$ & $\begin{array}{c}\text { Students } \\
\text { classification } \\
\text { based on } \\
\text { their } \\
\text { performance }\end{array}$ & $\begin{array}{c}\text { Students' } \\
\text { classification } \\
\text { based on } \\
\text { their } \\
\text { predicted } \\
\text { performance }\end{array}$ \\
\hline $\begin{array}{l}\text { 'Development of an intelligent } \\
\text { testing and diagnostic system on } \\
\text { computer networks' }\end{array}$ & 1999 & Yes & - & - \\
\hline $\begin{array}{l}\text { 'Fuzzy set approach to the } \\
\text { assessment of student-centered } \\
\text { learning' }\end{array}$ & 2000 & - & Yes & - \\
\hline
\end{tabular}


Table 1 Papers categorisation (continued)

\begin{tabular}{|c|c|c|c|c|}
\hline Title & Year & $\begin{array}{l}\text { Individual } \\
\text { characteristics } \\
\text { ladaptive } \\
\text { learning }\end{array}$ & $\begin{array}{c}\text { Students' } \\
\text { classification } \\
\text { based on } \\
\text { their } \\
\text { performance }\end{array}$ & $\begin{array}{c}\text { Students' } \\
\text { classification } \\
\text { based on } \\
\text { their } \\
\text { predicted } \\
\text { performance }\end{array}$ \\
\hline $\begin{array}{l}\text { 'Measuring the intellectual } \\
\text { development of students using } \\
\text { intelligent assessment software' }\end{array}$ & 2000 & - & Yes & - \\
\hline $\begin{array}{l}\text { 'Learning achievement } \\
\text { evaluation strategy using fuzzy } \\
\text { membership function' }\end{array}$ & 2001 & - & Yes & - \\
\hline $\begin{array}{l}\text { 'The intelligent assessment } \\
\text { system in web-based distance } \\
\text { learning education' }\end{array}$ & 2001 & Yes & Yes & - \\
\hline $\begin{array}{l}\text { 'Bayesian student modeling, } \\
\text { user interfaces and feedback: } \\
\text { a sensitivity analysis' }\end{array}$ & 2001 & - & Yes & - \\
\hline $\begin{array}{l}\text { 'Adaptive tutoring in } \\
\text { business education using } \\
\text { fuzzy backpropagation approach' }\end{array}$ & 2001 & Yes & - & - \\
\hline $\begin{array}{l}\text { 'Fuzzy inference for student } \\
\text { diagnosis in adaptive educational } \\
\text { hypermedia' }\end{array}$ & 2002 & - & Yes & - \\
\hline $\begin{array}{l}\text { 'Fuzzy logic applications to } \\
\text { students' evaluation in intelligent } \\
\text { learning systems' }\end{array}$ & 2003 & Yes & Yes & Yes \\
\hline $\begin{array}{l}\text { 'Two applications of Bayesian } \\
\text { networks' }\end{array}$ & 2003 & Yes & Yes & - \\
\hline $\begin{array}{l}\text { 'A neuro-fuzzy classification } \\
\text { approach to the assessment of } \\
\text { student performance' }\end{array}$ & 2004 & - & - & Yes \\
\hline $\begin{array}{l}\text { 'A neuro-fuzzy classification } \\
\text { approach to the assessment of } \\
\text { student performance' }\end{array}$ & 2004 & - & Yes & Yes \\
\hline $\begin{array}{l}\text { 'Development of a diagnostic } \\
\text { system of taxonomies using } \\
\text { fuzzy logic-case SOLO (useful } \\
\text { for e-learning system)' }\end{array}$ & 2004 & - & Yes & - \\
\hline $\begin{array}{l}\text { 'A neuro fuzzy inference system } \\
\text { for student modeling in web- } \\
\text { based intelligent tutoring } \\
\text { systems' }\end{array}$ & 2004 & Yes & Yes & - \\
\hline $\begin{array}{l}\text { 'Neuro-fuzzy knowledge } \\
\text { processing in intelligent } \\
\text { learning environments for } \\
\text { improved student diagnosis' }\end{array}$ & 2005 & Yes & - & - \\
\hline $\begin{array}{l}\text { 'Evaluation of fuzzy intelligent } \\
\text { learning systems' }\end{array}$ & 2005 & Yes & Yes & Yes \\
\hline
\end{tabular}


Table 1 Papers categorisation (continued)

\begin{tabular}{|c|c|c|c|c|}
\hline Title & Year & $\begin{array}{l}\text { Individual } \\
\text { characteristics } \\
\text { ladaptive } \\
\text { learning }\end{array}$ & $\begin{array}{l}\text { Students' } \\
\text { classification } \\
\text { based on } \\
\text { their } \\
\text { performance }\end{array}$ & $\begin{array}{l}\text { Students' } \\
\text { classification } \\
\text { based on } \\
\quad \text { their } \\
\text { predicted } \\
\text { performance }\end{array}$ \\
\hline $\begin{array}{l}\text { 'Neuro fuzzy reasoner for } \\
\text { student modeling' }\end{array}$ & 2006 & - & Yes & - \\
\hline $\begin{array}{l}\text { 'Inducing fuzzy models } \\
\text { for student classification' }\end{array}$ & 2006 & - & Yes & Yes \\
\hline $\begin{array}{l}\text { 'Bayesian student models based } \\
\text { on item to item knowledge } \\
\text { structures' }\end{array}$ & 2006 & - & - & Yes \\
\hline $\begin{array}{l}\text { 'Student modeling with atomic } \\
\text { Bayesian networks' }\end{array}$ & 2006 & - & Yes & - \\
\hline $\begin{array}{l}\text { 'A Bayes net toolkit for student } \\
\text { modeling in intelligent tutoring } \\
\text { systems' }\end{array}$ & 2006 & - & Yes & - \\
\hline $\begin{array}{l}\text { 'A tool set combining learning } \\
\text { styles prediction, a blended } \\
\text { learning methodology and } \\
\text { facilitator guidebooks - towards } \\
\text { a best mix in blended learning' }\end{array}$ & 2007 & Yes & - & - \\
\hline $\begin{array}{l}\text { 'Indirectly visible Bayesian } \\
\text { student models' }\end{array}$ & 2007 & Yes & Yes & - \\
\hline $\begin{array}{l}\text { 'Discovering student preferences } \\
\text { in e-learning' }\end{array}$ & 2007 & Yes & - & - \\
\hline $\begin{array}{l}\text { 'Research of student model } \\
\text { based on Bayesian network' }\end{array}$ & 2007 & Yes & Yes & - \\
\hline $\begin{array}{l}\text { 'The development of a self- } \\
\text { assessment system for the } \\
\text { learners answers with the use of } \\
\text { GPNN' }\end{array}$ & 2008 & - & Yes & - \\
\hline $\begin{array}{l}\text { 'Student modeling using } \\
\text { NN-HMM for EFL course' }\end{array}$ & 2008 & Yes & Yes & - \\
\hline $\begin{array}{l}\text { 'Evaluating students' } \\
\text { answerscripts using fuzzy } \\
\text { numbers associated with } \\
\text { degrees of confidence' }\end{array}$ & 2008 & - & Yes & - \\
\hline
\end{tabular}

\section{Conclusions}

The use of artificial intelligence methods in student modelling field has offered various new approaches in research on the educational field over the last decade. Indeed, each and every tool incorporated by researchers in the last years provides a valuable quality that brings us one step closer to flexible and reliable student modelling. Especially, 
hybrid methods that come up via combinations of two or more artificial intelligence tools (e.g., combining neural networks with fuzzy logic or neural networks with genetic programming) seem to optimise research results and that is why researchers will probably keep on emphasising on such approaches which is exactly what has been happening in the last decade and especially by 2004 . This relatively new direction is believed to be very hopeful since studies have shown that combining two or more tools, we can overcome several constraints that come up in case of separate application of the tools. In this context, we believe that neuro-fuzzy systems will continue to be one of the most popular researchers' choices as they are of high effectiveness in not only handling human uncertainty in a smooth way, but also to mimic in an impressive extent the way that the instructor adapts his decision-making to each student's individuality. The proposed synergy will be even more popular in the future if researchers focus on coming up with ways to lower the relatively high complexity that the particular combination of tools exhibits.

\section{References}

Al-Hammadi, A.S. and Milne, R.H. (2003) 'A neuro-fuzzy approach for student performance modeling', Electronics, Circuits and Systems, 2003. ICECS 2003. Proceedings of the 2003 10th IEEE International Conference, 2003, Vol. 3, pp.1078-1081.

Al-Hammadi, A.S. and Milne, R.H. (2004) 'A neuro-fuzzy classification approach to the assessment of student performance', IEEE in International Conference on Fuzzy Systems, July, Vol. 2, pp.837-841.

Alimisis, D., Moro, M., Arlegui, J., Pina, A., Frangou, S. and Papanikolaou, K. (2007) 'Robotics \& constructivism in education: the TERECoP project'.

Baylor, A.L. (1999) 'Intelligent agents as cognitive tools for education', Educational Technology, Vol. 39, No. 2, pp.36-40.

Biswas, R. (1995) 'An application of fuzzy sets in students' evaluation', Fuzzy Sets Syst., Vol. 74, No. 2, pp.187-194.

Blank, G.D., Parvez, S., Wei, F. and Moritz, S. (2005) 'A web-based its for OO design', poster for 12th International Conference on AIED, Workshop of Adaptive Systems for Web-Based Education: Tools and Reusability, Amsterdam, The Netherlands, June.

Brusilovsky, P. (1996) 'Methods and techniques of adaptive hypermedia', User Modeling and User-Adapted Interaction, Kluwer Academic Publ., Netherlands, Vol. 6, pp.87-129.

Brusilovsky, P. and Eklund, J. (1998) 'A study of user model based link annotation in educational hypermedia', Journal of Universal Computer Science, Vol. 4, No. 4, pp.429-448.

Carmona, C., Castillo, G. and Millán, E. (2007) 'Discovering student preferences in e-learning international workshop on applying data mining in e-learning (ADML'07)', at the Second European Conference on Technology Enhanced Learning (EC-TEL07), Crete, Greece, pp.33-42.

Chang, K.M., Beck, J.E., Mostow, J. and Corbett, A. (2006) 'A Bayes net toolkit for student modeling in intelligent tutoring systems', Proceedings of the 8th International Conference on Intelligent Tutoring Systems, Jhongli, Taiwan, pp.104-113.

Chen, S.M. and Lee, C.H. (1999) 'New methods for students' evaluating using fuzzy sets', Fuzzy Sets Syst., Vol. 104, No. 2, pp.209-218.

de Antonio, A., Ramirez, J., Imbert, R., Mendez, G. and Aguilar, R. (2005) 'A software architecturefor intelligent virtual environments applied to education', Rev. Fac. Ing. - Univ. Tarapacá, Vol. 13, No. 1, pp.47-55. 
de Arriaga, F., Arriaga, A., El Alami, M., Laureano-Cruces, A. and Ramírez-Rodríguez, J. (2003) 'Fuzzy logic applications to students' evaluation in intelligent learning systems', En Memorias XVI Congreso Nacional y II Congreso Internacional de Informática y Computación de la ANIEI, Zacatecas, 22-24 de Octubre del 2003, Vol. I, pp.161-166.

de Arriaga, F., El Alami, M. and Arriaga, A. (2005) 'Evaluation of fuzzy intelligent learning systems', in A. Méndez-Vilas et al. (Eds.): Recent Research Developments in Learning Technologies, Formatex.

Dean, T. and Kanazawa, K. (1989) 'A model for reasoning about persistence and causation', Computational Intelligence, Vol. 5, pp.142-150.

Desmarais, M. and Gagnon, M. (2006) 'Bayesian student models based on item to item knowledge structures, n', Proceedings of the 1st European Conference on Technology-Enhanced Learning, Springer, Heidelberg, Vol. 4227, pp.111-124.

Díez, F.J. (1994) 'Sistema experto Bayesiano para ecocardiografía', PhD dissertation, Dpto. Informática y Automática, Madrid, UNED.

Drigas, A., Vrettaros, J. and Kouremenos, D. (2004a) 'Teleeducation and e-learning services for teaching English as a second language to deaf people, whose first language is the sign language', WSEAS Transactions on Information Science and Applications, September, Vol. 1, No. 3.

Drigas, A.S. and Vrettaros, J. (2004) 'An intelligent tool for building e-learning contend-material using natural language in digital libraries', Proceedings of WSEAS Int. Conf. on E-AVTIVITIES (E-AVTIVITIES 2004), Rethymno, Crete, Greece, 24-26 October, selected and is included also in WSEAS Transactions on Information Science and Applications, November, Vol. 1, No. 5.

Drigas, A.S., Vrettaros, J., Stavrou, L. and Kouremenos, D. (2004b) 'Elearning environment for deaf people in the e-commerce and new technologies sector', 6th WSEAS International Conference on EACTIVITIES, Rethymno, 20 October.

Felder, R.M. and Soloman, B.A. (2007) Index of Learning Style Questionnaire.

Felder, R.M. and Spurlin, J. (2005) 'Applications, reliability and validity of the index of learning styles', Int. J. Engng. Ed., Vol. 21, No. 1, pp.103-112.

Frias-Martinez, E., Magoulas, G.D., Chen, S.Y. and Macredie, R.D. (2005) 'Modeling human behavior in user-adaptive systems: recent advances using soft computing technique', Expert Systems with Applications, Vol. 29, No. 2.

Friedman, N., Geiger, D. and Goldszmidt, M. (1997) 'Bayesian network classifiers', Machine Learning, Vol. 29, Nos. 2-3, pp.131-163.

Grigoriadou, M., Kornilakis, H., Papanikolaou, K. and Magoulas, G. (2002) 'Fuzzy inference for student diagnosis in adaptive educational systems', in I.P. Vlahavas and C.D. Spyropoulos (Eds.): Methods and Applications of Artificial Intelligence, Lecture Notes in Artificial Intelligence, Vol. 2308, pp.191-202, Springer-Verlag, Berlin.

Haron, N. and Salim, N. (2005) 'Individualizing learning material of adaptive hypermedia learning system based on personality factor (MBTI) using fuzzy logic techniques'.

Hawkes, L.W., Derry, S.J. and Rundensteiner, E.A. (1990) 'Individualized tutoring using an intelligent fuzzy temporal relational database', International Journal of Man-Machines Studies, Vol. 33, pp.409-429.

Heckerman, D.E., Horvitz, E. and Nathwani, B. (1989) 'Update on the pathfinder project', Proceedings of the Thirteenth Symposium on Computer Applications in Medical Care, Washington, DC.

Homsi, M., Lutfi, R., Rosa, M.C. and Barakat, G. (2008) 'Student modeling using NN - HMM for EFL course, information and communication technologies: from theory to applications', ICTTA 2008. 3rd International Conference, 7-11 April, pp.1-6.

Hwang, G.J. (1999) 'Development of an intelligent testing and diagnostic system on computer networks', Proceedings of the National Science Council of ROC, Vol. 9, No. 1, pp.1-9. 
Kinshuk, A., Nikov, A. and Patel, A. (2001) 'Adaptive tutoring in business education using fuzzy backpropagation approach', in Proceedings of the Ninth International Conference on Human-Computer Interaction, pp.465-468.

Kwok, R. and Ma, J. (1999) 'Use of group support system for collaborative assessment', Comput. Educ. Int. J., Vol. 32, pp.109-125

Lane, H.C. (2006) 'Intelligent tutoring systems: prospects for guided practice and efficient learning', White paper for the Army's Science of Learning Workshop, Hampton, VA, $1-3$ August.

Li, D-Y., Liu, C-Y. and Du-He, H-X. (2004) 'Artificial intelligence with uncertainty', Journal of Software 2004, Vol. 15, No. 11, pp.1583-1594.

Liao, S-H. (2005) 'Expert system methodologies and applications - a decade review from 1995 to 2004', Expert Syst. Appl., Vol. 28, No. 1, pp.93-103.

Ma, J. (1996) 'Group decision support system for assessment of problem-based learning', IEEE Trans. Educ., Vol. 39, pp.388-393.

Ma, J. and Zhou, D. (2000) 'Fuzzy set approach to the assessment of student-centered learning', IEEE Trans. Educ., Vol. 43, pp.237-241.

McAlister, M. and Wermter, S. (1999) 'Rule generation from neural networks for student assessment', Proceedings of the International Joint Conference on Neural Networks, Washington, USA, July.

Mir Sadique, A. and Ghatol, A.A. (2004) 'An adaptive neuro fuzzy inference system for student modeling', in Web-Based Intelligent Tutoring Systems.

Moebs, S., Piombo, C., Batatia, H. and Weibelzahl, S. (2007) 'A tool set combining learning styles prediction, a blended learning methodology and facilitator guidebooks - towards a best mix in blended learning', in Proceedings Interactive Computer Aided Learning, Villach, Austria.

Moritz, S. and Blank, G.D. (2005) 'A design-first curriculum for teaching java in a CS1 course', ACM SIGCSE Bulletin Archive, June, Vol. 37, No. 2, pp.89-93.

Moritz, S., Wei, F., Parvez, S. and Blank, G.D. (2005) 'From objects-first to design-first with multimedia and intelligent tutoring', The Tenth ITiCSE, Monte da Caparica, Portugal, June.

Mostow, J. and Aist, G. (2001) 'Evaluating tutors that listen: an overview of project LISTEN', in K. Forbus and P. Feltovich (Eds.): Smart Machines in Education, pp.169-234, MIT/AAA Press, Menlo Park, CA.

Nykänen, O. (2006) 'Inducing fuzzy models for student classification', Educational Technology \& Society, Vol. 9, No. 2, pp.223-234.

Olds, B., Miller, R. and Pavelich, M. (2000) 'Measuring the intellectual development of engineering students using intelligent assessment software', Proceedings of the International Conference on Engineering Education, Taipei, Taiwan, 14-18 August.

Russell, S. and Norvig, P. (1995) Artificial Intelligence: A Modern Approach, Morgan-Kaufman, Los Altos, CA.

Salleh, N.S.M., Jais, J., Mazalan, L., Ismail, R., Yussof, S., Ahmad, A., Anuar, A. and Mohamad, D. (2007) 'Sign language to voice recognition: hand detection techniques for vision-based approach', Uniten Student Conference on Research and Development (SCOReD), 14-15 May.

Sevarac, Z. (2006) 'Neuro fuzzy reasoner for student modeling', Proceedings of the Sixth International Conference on Advanced Learning Technologies, pp.740-744.

Shen, R., Tang, Y. and Zhang, T. (2001) 'The intelligent assessment system in web-based distance learning education', in 31th ASEE/IEEE Frontiers in Education Conference.

Siddique, M.N.H. and Tokhi, M. (2001) 'Training neural networks: backpropagation vs. genetic algorithms', in Proceedings of the IEEE International Joint Conference on Neural Networks, Vol. 4, pp.2673-2678. 
Stathakopoulou, R., Magoulas, G., Grigoriadou, M. and Samarakou, M. (2005) 'Neuro-fuzzy knowledge processing in intelligent learning environments for improved student diagnosis', Information Sciences, Vol. 170, pp.273-307.

VanLehn, K. and Niu, Z. (2001) 'Bayesian student modeling, user interfaces and feedback: a sensitivity analysis', International Journal of Artificial Intelligence in Education, Vol. 12, pp.154-184.

Vomlel, J. (2003) 'Two applications of Bayesian networks', in Proceedings of conference Znalosti 2003, Ostrava, Czech Republic, February, pp.73-82.

Vrettaros, J., Pavlopoulos, J., Vouros, G.A. and Drigas, A. (2008) 'The development of a selfassessment system for the learners answers with the use of GPNN', WSKS, No. 1, pp.332-340.

Vrettaros, J., Vouros, G. and Drigas, A. (2004) 'Development of a diagnostic system of taxonomies using fuzzy logic - case solo (useful for e-learning system)', Proceedings of 5th WSEAS International Conference on AUTOMATION \& INFORMATION (ICAI'04), Venice, Italy, 15-17 November, selected and is included also in WSEAS Transactions on Information Science and Applications, December, Vol. 1, No. 6.

Wang, H-Y. and Chen, S-M. (2008) 'Evaluating students' answerscripts using fuzzy numbers associated with degrees of confidence', IEEE Transactions on Fuzzy Systems, April, Vol. 16, No. 2.

Wei, F. and Blank, G.D. (2006) 'Student modeling with atomic Bayesian networks', The 8th International Conference on Intelligent Tutoring Systems.

Wei, F., Moritz, S., Parvez, S. and Blank, G.D. (2005) 'A student model for object-oriented design and programming', The Journal of Computing Sciences in Colleges (CCSC), Vol. 20, pp.260-273.

Weon, S. and Kim, J. (2001) 'Learning achievement evaluation strategy using fuzzy membership function', in Proceedings of the 31st ASEE/IEEE Frontiers in Education Conference, Reno, NV, Vol. 1, pp.19-24.

Yang, Q., Wang, X., Huang, Z. and Zheng, S. (2007) 'Research of student model based on Bayesian network, information technologies and applications in education', ISITAE Apos; 07, First IEEE International Symposium, 23-25 November, pp.514-519.

Zadeh, L.A. (1965) 'Fuzzy sets', Information and Control, pp.338-353.

Zapata-Rivera, D. (2007) 'Indirectly visible Bayesian student models', Proceedings of the 5th UAI Bayesian Modelling Applications Workshop, CEUR Workshop Proceedings, Vol. 268.

Zhou, D., Ma, J., Kwok, R.C.W. and Tian, Q. (1999) 'Group decision support system for project assessment based on fuzzy set theory', presented at the Proc. 32nd Hawaii Int. Conf. System Sciences (HICSS-32), Honolulu, HI, January. 